\title{
Advancing Care Together by Integrating Primary Care and Behavioral Health
}

\author{
Larry A. Green, MD, and Maribel Cifuentes, RN, BSN
}

Keywords: Delivery of Health Care, Integrated; Mental Health; Mind-Body Medicine; Primary Health Care (J Am Board Fam Med 2015;28:S1-S6.)

Separating the care of people with emotional and behavioral problems into physical and mental compartments and organizing 2 systems of care to meet their needs has been known to be a mistake for decades. ${ }^{1-3}$ Progress on actually changing clinical practice to integrate care has been slow, not so much because of neglect, but because it is hard, often challenged by history, clashing cultures, and institutionalized barriers. ${ }^{4,5}$

The case for replacing current approaches with revised practices and services to care for people with behavioral health conditions is strong, and includes opportunities to improve health and health care, and to contain health care expenses. ${ }^{6-10}$ Figure 1 depicts the prevalence and unmet need for treatment of mental health disorders, and makes the case for behavioral health and primary care integration.

As the delivery of integrated care continues to mature, so too has the lexicon associated with it. In this supplement we use the following definitions adapted from the work of Peek ${ }^{11}$ and Butler and colleagues. ${ }^{12}$ Behavioral health care is used as a broad term to encompass care for patients around mental health and substance use conditions, health

This article was peer reviewed.

Submitted 20 March 2015; revised 22 May 2015; accepted 5 June 2015.

From the Department of Family Medicine, University of Colorado School of Medicine, Aurora, CO.

Funding: This research was supported by grants from the Colorado Health Foundation (CHF-3848), Agency for Healthcare Research and Quality (8846.01-S01), Tides Foundation/CalMHSA Integrated Behavioral Health Project (AWD-131237), and Maine Health Access Foundation (2012FI-0009).

Conflict of interest: none declared.

Corresponding author: Larry A. Green, MD, Department of Family Medicine, University of Colorado School of Medicine, 12631 East 17th Avenue, Mail Stop F496, Aurora, CO 80045 (E-mail: larry.green@ucdenver.edu). behavior change, life stressors and crises, as well as stress-related physical symptoms. The term integrated care is used to mean care rendered by a practice team of primary care and behavioral health clinicians, working together with patients and families and using a systematic and cost-effective approach to provide patient-centered care that addresses diverse physical health and behavioral health needs. ${ }^{11,12}$

There are opportunities to close the gap between what we know and what we do. ${ }^{13}$ The large segment of the population burdened by behavioral health problems ${ }^{14,15}$ is waiting for health professionals to unite and work together to meet their needs. It is a situation calling for swift, assertive action. Fortunately, community-based practices are rising to the challenge, such as those that participated in Advancing Care Together (ACT) and the Integrated Workforce Study (IWS). ACT and IWS were 2 comparative case studies conducted by an independent and experienced evaluation team at Oregon Health \& Science University. These studies provided the evidence for this supplement.

ACT was a program sponsored by the Colorado Health Foundation and administered by the Department of Family Medicine at the University of Colorado-Denver. The aim of this 5-year enterprise was to change practice, specifically primary care practices and community mental health centers in different settings and working with different populations under different business models. A statewide competition invited local clinicians to propose their own ideas regarding how they could make progress toward integrating the care of their patients with behavioral health conditions. A steering committee of local and national leaders selected eleven practices reflecting the diversity of ideas and situations that applicants proposed. Minimal fund- 
Figure 1. A case for integrating behavioral health and primary care. Reproduced with permission from the Eugene S. Farley, Jr. Health Policy Center.
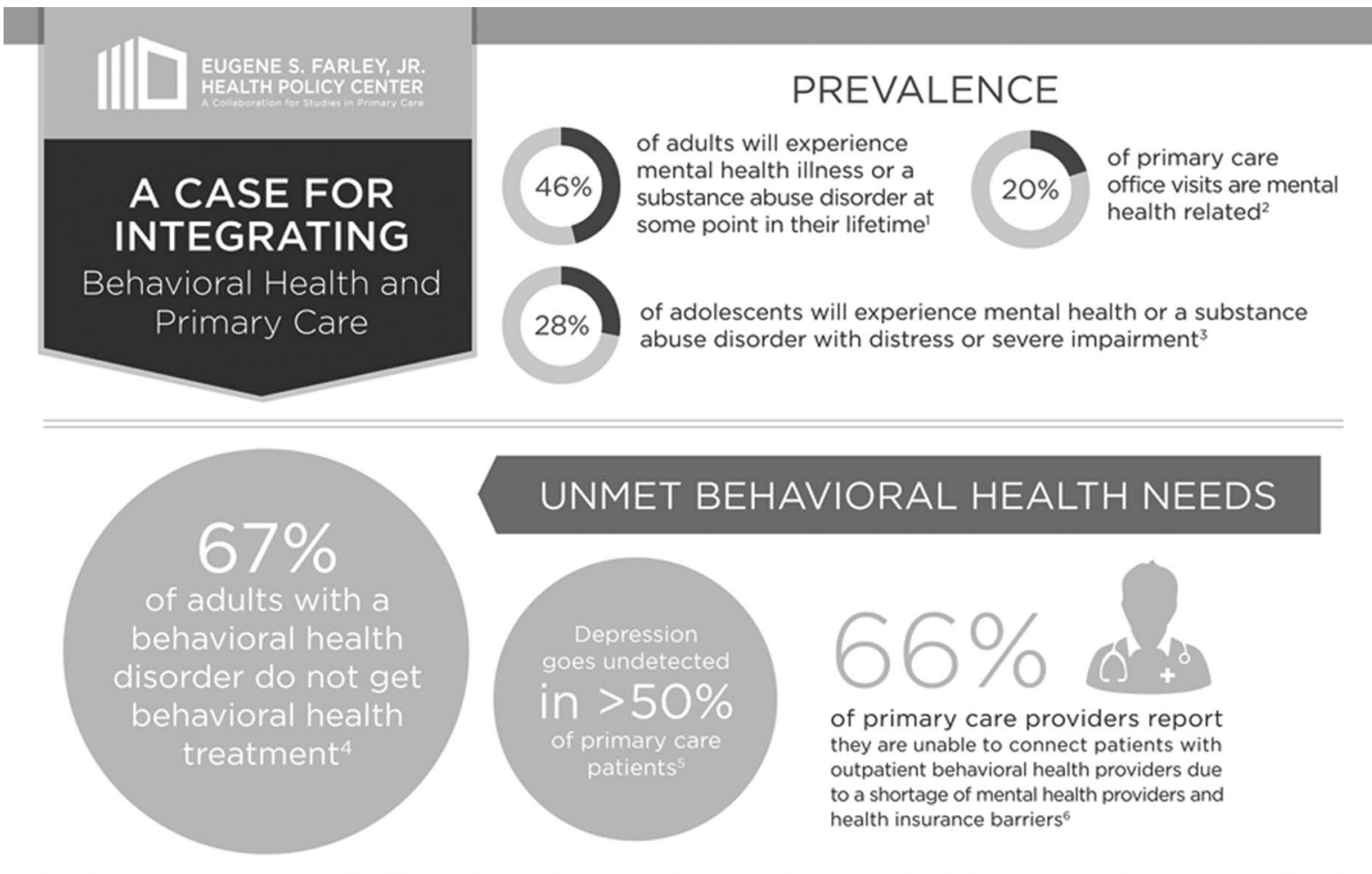

\section{UNMET BEHAVIORAL HEALTH NEEDS}

\section{WHY PROVIDERS LIKE \\ INTEGRATED PRIMARY CARE?}

Better communication

$>$ More comprehensive services

Better management of depression, anxiety and alcohol abuse

$>$ More convenient services for patients

$>$ Less stigma for patients

$>$ Better coordination of mental and physical health

$>$ Quicker appointments for mental health services

$>$ Better health education

\section{TOP 5 CONDITIONS DRIVING OVERALL HEALTH COST $^{8}$}

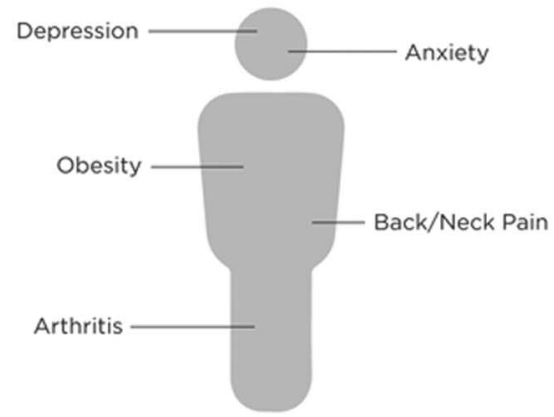

When treated in harmony with mental health, chronic physical health improves significantly, along with

'Kessler RC, Wang PS. The descriptive epidemiology of commonly occurring mental disorders in the United States. Annual review of public health. 2008;29:115-29.
'Center for Disease Control and Prevention. Percentage of Mental Health-Related Primary Care Office Visits, by Age Group - National Ambulatory Medical Care Survey, United States, 2010. Morbidity and Mortality Weokly Report. 2014;63(47);1118. 'Merikangas, K. R, et al. (2010). Lifetime prevalen
Child Adolesc Psychiatry 2010:49(10) 980.989 .

" Kessler RC, Demler O, Frank RG, Olfson M, Pincus HA, Walters EE, et al. Prevalence and treatment of mental disorders, 1990 to 2003. The New England journal of medicine. 2005:352(24):2515-23. "Mitchell A, Vaze A, Rao S. Clinical diagnosis of depression in primary care: a meta-analysis. Lancet. 2009:374(9690):609-19.

- Cunningham PJ. Beyond parity: primary care physict

' Gallo J. Zubritsky C. Maxwell J. Nazar M, Bogner HR, Quijano LM, et al. Primary care clinicians evaluate integrated and referral models of behavioral health care for older adults: results from

- Loeppke R, Taitel M, Haufle V. Parry T. Kessler RC, Jinnett K. Health and productivity as a business strategy: a multiemployer study. Journal of occupational and environmental medicine / American College of Occupational and Environmental Medicine. 2009:51(4):411-28.

'Katon WJ, Lin EH, Von Korff M, Ciechanowski P, Ludman EJ. Young B, et al. Colloborative care for patients with depression and chronic illnesses.
The New England journal of medicine. 2010:363(27):2611-20.

52015 Eugenes. Farley, Jc. Heath Policy Center 
ing $(\$ 150,000$ total over $3 \mathrm{y})$ was provided to cover practice expenses associated with their participation in ACT and the program's crosscutting evaluation and learning community. The aim of the ACT evaluation was to learn what practices aspired and were able to do under their local conditions and with local resources, to improve the care of people with emotional and behavioral problems. The evaluation examined how practices implemented their ideas, what happened to the practices as they proceeded with their plans and the resulting effects on a set of variables that matter to patients, clinicians, and policy makers. Early ACT results and a description of the structure and methods of the evaluation have been published. ${ }^{16}$

The IWS was sponsored by the Agency for Health care Research and Quality, the Maine Health Access Foundation, and the CalMHSA Foundation. IWS provided an opportunity to assess practices outside of Colorado and to assist the field of primary care and behavioral health in identifying professional practices and core competencies for developing a workforce for integrated care. The practices were selected through a key informant nomination process to identify candidate practices with successful experience integrating care. The evaluation team and a consultant panel reviewed nominations and made preliminary inquiries, and then an expert panel selected practices for direct observation and evaluation. Eight sites were selected across the United States with different levels of maturity and duration of their integration approaches. The IWS evaluation sought to discern what exemplary integrated practices actually do to achieve high-quality integrated care. Given that the vast majority of other competency efforts around integration had been focused on only using the literature or a consensus panel, this effort was different in that it relied on the direct observation of practices and focused on how integrated care was organized and accomplished. The IWS concluded with the creation of a Guidebook of Professional Practices for Behavioral Health and Primary Care Integration: Observations from Exemplary Sites. ${ }^{17}$

This supplement pulls together key lessons learned from ACT and IWS about what it takes to implement integrated care, not under well-funded research conditions, but in the diverse, local realities of frontline practices with varying levels of experience. The primary audience for this material is frontline clinicians and practices who want to improve the care of people with emotional and behavioral problems and join the movement to replace the separated histories of so-called physical and mental health care with evidence-based, integrated care that works. Additional audiences include funders of practice transformation initiatives, practice change facilitators, and others in a position to enable practice transformation through their efforts, such as those positioned to implement payment and workforce reforms.

The articles in the supplement can be extracted according to a reader's particular interest, but taken together they contribute to an emerging picture of complexity, challenge, success, and struggle during the journey to integration of primary care and behavioral health. They are about the "how" of integrated behavioral health and primary care.

In this supplement, readers will find descriptions and observations about a number of elements that are keenly important in shaping how integrated care is organized and delivered in clinical settings. Gunn et $\mathrm{al}^{18}$ report how the physical design and floor plans of practices enabled or impeded integrated care and offer recommendations anyone with an opportunity to remodel or build new space may find useful, including a starter template. Hall et $\mathrm{al}^{19}$ identified a half dozen ways practices coped with the unfortunate fact that the available primary care and behavioral health care workforce typically does not come fully equipped with training and prior experience to work effectively in integrated practices. Health professions educators may spot opportunities to improve their graduates' preparation for integrated practice. Davis et $\mathrm{al}^{20}$ report details of staffing ratios and scheduling patterns and expose observed consequences to clinicians, staff, and patients attributable to the number and types of clinicians, their locations, and their occasional or constant availability. Cifuentes et $\mathrm{al}^{21}$ go past the usual complaints about electronic health records (EHRs) to reveal observed workarounds deployed by practices to cope with the data collection and sharing requirements of integrated care. EHR vendors have opportunities to help patients get what they need by making these workarounds unnecessary.

Cohen et $\mathrm{al}^{22}$ serve up a feast of insight into how primary care and behavioral health clinicians actually were observed to work together in daily practice, deploying 3 distinct work modes. Practices and educators will want to check out the patient, 
clinician, practice and system factors that support what looks like a dance of collaboration. Balasubramanian et $\mathrm{al}^{23}$ demonstrate 2 practical approaches to measuring REACH (the extent to which the integration program was delivered to the identified target population), defined within the RE-AIM (Reach Effectiveness Adoption Implementation Maintenance) evaluation framework as the absolute number, proportion, and representativeness of individuals who participate in a given initiative, intervention, or program. ${ }^{24}$ The wide variation in REACH among practices sends a sobering message of how a lot of hard work may not yield desired results, but also how measuring REACH can prompt revising or solidify ongoing implementation. Wallace et $\mathrm{al}^{25}$ report a nearly heroic effort to make sense of the expenditures ACT practices made as they implemented and operated their integration strategies. Payers will not see the numbers they need to adjust payments, but they will see that integration of primary care and behavioral health is not free, where expenses are incurred, and that payment must be adjusted if integrated care is to be promulgated and sustained. Cohen et $\mathrm{al}^{26}$ cast a gaze across these practices to reveal organizing constructs that within the context of each practice produce different expressions of what integrated care can look like in diverse practice settings. Both practices and researchers may find that these constructs can guide their efforts to implement and further understand integrated care.

This supplement also contains stories about provider and patient successes and struggles that move beyond words to understanding of what it is going to take to do right by millions of people awaiting the fruits of scientific knowledge and redesigned practice. Three invited commentaries on leadership, policy, and practice assistance ${ }^{27,28,29}$ conclude the supplement offering interpretations and suggestions about next steps, which are urgently needed to continue to move forward toward the integration of behavioral health and primary care.

This type of investigation and approach to discovery depends fundamentally on the ability and willingness of real practices in real communities taking care of real people to disrupt their daily lives to share what they know and what they do with researchers in hopes of doing better. ACT is thus indebted to the eleven innovating practices that came together to lead and learn together and to expose themselves and their work to scrutiny. This was an act of courage and professionalism for which we express our deep appreciation and admiration. The 11 that began the ACT journey ended the ACT journey together, albeit not necessarily in the same configuration nor having done everything they thought they would do in a particular manner. These practices are listed below. Like the ACT practices, those that participated in IWS opened themselves to intense scrutiny, including direct observation of patient care, and shared freely their hard-won lessons and approaches to integrated care. We also owe a great debt and extend our gratitude to these practices, also listed below.

These innovators continue serving their local communities having made progress toward better care for their patients. This supplement attempts to draw lessons from their journey, especially about how integrated care can be done. The nation's journey toward integrated care continues and begs to be accelerated. So many people are waiting for care that integrates the mind and body, primary care, and behavioral health. It will be done and become the standard of practice. The question now is when?

\section{ACT Practices}

- Axis Health System, Durango, CO

- Bender Medical Group, Inc., Fort Collins, CO

- Denver Health and Hospital, Denver, CO

- Jefferson Center for Mental Health, Wheat Ridge, CO

- Kaiser Permanente Colorado, Denver, CO

- Midvalley Family Practice, Basalt, CO

- Plan de Salud del Valle Inc., Brighton, CO

- Primary Care Partners, Grand Junction, CO

- Southeast Mental Health Services, La Junta, CO

- University of Colorado Aging Center, Colorado Springs, CO

- Westminster Medical Clinic Westminster, CO

\section{IWS Practices}

- Cherokee Health Systems, Knoxville, TN

- Edward Hines, Jr. VA Hospital-Primary Care Behavioral Health Program, Hines, IL

- Fairview Clinics-Integrated Primary Care, Fairview Health Services, Minneapolis, MN 
- Golden Valley Health Centers, Merced, CA

- Institute for Family Health, New York, NY

- Penobscot Community Health Care-Summer Street Health Center, Bangor, ME

- Southcentral Foundation, Anchorage, AK

- Swift River Family Medicine, working in collaboration with Tri-County Mental Health Services, Rumford, ME

\section{References}

1. deGruy F. Mental health care in the primary care setting. In: Donaldson MS, Yordy KD, Lohr KN, Vanselow NA, eds. Primary care: America's health in a new era. Washington, DC: Institute of Medicine, 1996.

2. Institute of Medicine. Committee on crossing the quality chasm: Adaptation to mental health and addictive disorders. National Academy of Sciences, 2006.

3. Miller BF, Talen MR, Patel KK. Advancing integrated behavioral health and primary care: The critical importance of behavioral health in health care policy. In: Talen MR, Valeras $\mathrm{AB}$, eds. Integrated behavioral health in primary care: Evaluating the evidence, identifying the essentials. New York: Springer, 2013.

4. Blount A, ed. Integrated primary care: The future of medical and mental health collaboration. New York: Norton, 1998.

5. Kathol RG, Butler M, McAlpine DD, Kane RL. Barriers to physical and mental condition integrated service delivery. Psychosom Med 2010;72: 511-518.

6. Tice JA, Ollendorf DA, Reed SJ, Shore KK, Weissberg J, Pearson SD. Integrating behavioral health into primary care. institute for clinical and economic review. Available from: http://ctaf.org/sites/default/ files/u148/CTAF_BHI_Draft_Report_031115R.pdf. Accessed May 15, 2015.

7. AcademyHealth. Evidence Roadmap: Integration of physical and behavioral health services for medicaidenrollees.May2015.Availablefrom:http:// www.academyhealth.org/files/FileDownloads/ Roadmap.BehavioralHealth.pdf

8. Kwan B, Nease D Jr. The state of the evidence for integrated behavioral health in primary care. In: Talen MR, Burke Valeras A, eds. Integrated behavioral health in primary care: New York: Springer, 2013;65-98.

9. Melek S, Norris D. Chronic conditions and comorbid psychological disorders. Seattle: Milliman, 2008.

10. Miller BF, Brown Levey S, Payne-Murphy JC, Kwan B. Outlining the scope of behavioral health practice in integrated primary care: Dispelling the myth of the one-trick mental health pony Fam Syst Health. 2014;32(3):338-43.
11. Peek CJ, National Integration Academy Council. Lexicon for behavioral health and primary care integration: concepts and definitions developed by expert consensus. Rockville, MD: Agency for Healthcare Research and Quality, 2013. Available from: http://integrationacademy.ahrq.gov/sites/ default/files/Lexicon.pdf. Accessed July 19, 2015.

12. Butler M, Kane RL, McAlpine D, et al. Integration of mental health/substance abuse and primary care. Evidence report/technology assessment no. 173. Rockville, MD: Agency for Healthcare Research and Quality, 2008. Available from: http:// www.ahrq.gov/research/findings/evidence-basedreports/mhsapc-evidence-report.pdf. Accessed July 19, 2015.

13. Institute of Medicine. Crossing the quality chasm: A new health system for the 21st century. Washington, DC: National Academy Press, 2001.

14. Levey SM, Miller BF, Degruy FV 3rd. Behavioral health integration: Behavioral health integration: an essential element of population-based healthcare redesign. Transl Behav Med. 2012;2(3):36471.

15. Petterson S, Miller BF, Payne-Murphy JC, Phillips RL Jr. Mental health treatment in the primary care setting: Patterns and pathways. Fam Syst Health 2014;32(2):157-66.

16. Davis M, Balasubramanian BA, Waller E, Miller BF, Green LA, Cohen DJ. Integrating behavioral and physical health care in the real world: early lessons from advancing care together. J Am Board Fam Med 2013;26:588-602.

17. Cohen DJ, Davis MM, Hall JD, Gilchrist IC, Miller BF. A guidebook of professional practices for behavioral health and primary care integration: Observations from exemplary sites. Rockville, MD: Agency for Health Care Research and Quality, 2015.

18. Gunn R, Davis M, Hall J, et al. Designing clinical space for the delivery of integrated behavioral health and primary care. J Am Board Fam Med 2015;28: S52-S62.

19. Hall J, Cohen DJ, Davis M, et al. Preparing the workforce for behavioral health and primary care integration. J Am Board Fam Med 2015;28:S41-S51.

20. Davis MM, Balasubramanian BA, Fernald D, et al. Clinician staffing, scheduling, and engagement strategies among primary care practices. delivering integrated care. J Am Board Fam Med 2015;28: S32-S40.

21. Cifuentes M, Davis M, Gunn R, Fernald D, Dickinson WP, Cohen D. Electronic health record challenges, workarounds, and solutions observed in practices integrating behavioral health and primary care. J Am Board Fam Med 2015;28:S63-S72.

22. Cohen DJ, Davis M, Balsubramanian BA, et al. Integrating behavioral health and primary care: consulting, coordinating and collaborating among 
professionals. J Am Board Fam Med 2015;28:S21S31.

23. Balasubramanian BA, Fernald D, Dickinson LM, et al. REACH of interventions integrating primary care and behavioral health. J Am Board Fam Med 2015; 28:S73-S85.

24. Glasgow RE, Vogt TM, Boles SM. Evaluating the public health impact of health promotion interventions: the RE-AIM framework. Am J Public Health (N Y). 1999;89:1322-1327.21.

25. Wallace NT, Cohen DJ, Gunn R, et al. Start-up and ongoing practice expenses of behavioral health and primary care integration interventions in the Advancing Care Together (ACT) program. J Am Board Fam Med 2015;28:S86-S97.
26. Cohen DJ, Balasubramanian BA, Davis M, et al. Understanding care integration from the ground up: five organizing constructs that shape integrated practices. J Am Board Fam Med 2015;28:S7-S20.

27. DeGruy FV. Integrated care: tools, maps, and leadership. J Am Board Fam Med 2015;28:S107-S110.

28. Miller BF. When frontline practice innovations are ahead of the health policy community: the example of behavioral health and primary care integration. J Am Board Fam Med 2015;28:S98-S101.

29. Dickinson WP. Strategies to support the integration of behavioral health and primary care: what have we learned thus far? J Am Board Fam Med 2015;28: S102-S106. 